\title{
Behavioural Deprivation: A Central Problem in Animal Welfare
}

\author{
MARIAN STAMP DAWKINS \\ Animal Behaviour Research Group, Department of Zoology, University of Oxford (Gt. Britain)
}

(Accepted for publication 27 January 1988)

\section{ABSTRACT}

Dawkins, M.S., 1988. Behavioural deprivation: a central problem in animal welfare. Appl. Anim. Behav. Sci., 20: 209-225.

A key issue in animal welfare is whether keeping animals in conditions where they cannot or do not perform behaviour typical of more naturally-kept members of their species causes them to suffer. Various measures have been used to resolve this issue. The cost an animal is prepared to pay for the opportunity to perform different behaviour can be used as a measure of the importance of that behaviour to the animal. Manipulation of time-budgets is the most reliable method of measuring such costs and of relating "deprivation" to "suffering".

\section{INTRODUCTION}

To be concerned about animal welfare is to be concerned with the subjective feelings of animals, particularly the unpleasant subjective feelings of suffering and pain (Dawkins, 1980; Baxter, 1983b; van Rooijin, 1984; Zayan and Duncan, 1987). One of the most important tasks in the study of animal welfare is, therefore, to identify observable external indicators of these internal subjective feelings. Of these, health criteria are the least controversial, since disease and injury are widely accepted as sources of suffering (e.g. Loliger, 1985). However, where the animal is apparently healthy and the suffering, if it exists, does not result in clinical symptoms, there is still a need to clarify which indicators, both physiological and behavioural, are the most useful (van Putten, 1981; Brown, 1981; Tschantz, 1982; Banks, 1982; Dantzer et al., 1983; Smidt, 1983; Craig and Adams, 1984; Duncan 1974; Ewbank, 1985; McBride and Craig, 1985).

The problem is not, however, just that of deciding which physiological or behavioural variables to look at, but of knowing how much of a change in these variables constitutes suffering (Hill, 1983; Kilgour, 1985; Barnett et al., 1985). Changes in hormone levels or in the frequency of certain sorts of behaviour do not in themselves constitute suffering (Hughes, 1980). What is of concern 
from the welfare point of view is whether the conditions that give rise to these changes actually matter to the animals.

In the absence of clinical signs of disease or injury, most suffering (here taken to mean intensely and/or enduring unpleasant subjective feelings) can be divided into two categories:

(1) Suffering caused by the presence of conditions or treatments that an animal is motivated to get away from or avoid but cannot (aversion);

(2) Suffering caused by the absence of certain conditions, where the animal is motivated to perform a behaviour but unable to perform it because of physical restraint or lack of suitable stimuli (deprivation).

In both aversion and deprivation, the animal is motivated to do something but prevented from doing it. In both cases there is the further implication that this state of being prevented from behaving in certain ways has to be either intense or prolonged or both (van Rooijen, 1984) to count as suffering, since an animal that had a mild temporary itch it could not scratch would not be said to be "suffering". The key to recognizing suffering is, therefore, to establish how strongly the animal is motivated to do something (Dawkins, 1983a, b).

Following Russell and Burch's original (1959) suggestion, Rushen (1986a,b) has recently reviewed some of the techniques of aversion-learning that can be used to determine the aversiveness of various husbandry treatments to animals, using the "cost" the animal is prepared to pay to avoid them. He argues that "cost" can be gauged by comparison with the effects of electric shock, specifically, on conditioned suppression of previously learned habits. This approach is highly promising for establishing the aversiveness of transitory procedures, such as the way an animal is handled before capture and loading. Longer-term effects leading to "deprivation" where an animal may be housed in conditions that prevent it from performing many of its behaviour patterns for long periods of time require a somewhat different approach. Nevertheless, measuring the "cost" an animal is prepared to pay to change its situation or to avoid change may, even for chronic long-term states, be the most direct method we have of establishing whether the animal suffers (Rawlins et al., 1980). The purpose of this paper is to examine the various ways in which this might be achieved and to argue that manipulation of time-budgets is the most promising.

\section{WHAT IS DEPRIVATION?}

Behavioural deprivation implies not only that an animal is prevented from performing behaviour that a less restricted member of its species would perform, but also that adverse effects arise as a result. Thorpe $(1965,1967)$ believed that animals suffered if unable to perform the full repertoire of behaviour shown "in nature", a view supported by Martin (1975) and more recently by the Farm Animal Welfare Council (1986). 
However, the mere existence of differences in behaviour between two groups of animals (e.g. intensively housed and free-range) does not necessarily imply "deprivation" or suffering, for the following reasons:

(1) the animal may have acclimatized or adapted to its environment, e.g. tameness shown by a zoo animal to its keeper.

(2) there may be genetic differences between the intensively housed and the wild or feral animals used for comparison (Wood-Gush, 1973; Beilharz and Zeeb, 1981).

(3) behaviour strongly dependent on external stimuli (e.g. anti-predator behaviour) may not be shown in an intensive system because of the absence of the suitable eliciting stimuli (Hughes, 1980), or the animal may be provided with food and nesting material and so not be motivated to seek them out as it would do in the wild (Baxter, 1983b).

Lorenz's (1950) view that all behaviour resulted from the accumulation of "motivational energy" that built up over time and needed to be discharged has been replaced by the realisation that motivation underlying different behaviours may be very different (Hinde, 1970; Lorenz, 1978; Hughes, 1980; Halliday, 1983). The consequences of not performing a behaviour may also be very variable. In some cases, the deprived animal may undergo an increasing motivation to do the prevented behaviour (e.g. drinking) and suffering results if the deprivation continues. In other cases, "out of sight" is "out of mind" and the "deprived" animal is not motivated to do the behaviour even if it has not performed it for a long time (Heiligenberg and Kramer, 1972). It is now clear that deprivation of some activities has far more serious welfare consequences than deprivation of others (Nicol, 1987).

"Suffering through deprivation" is sometimes expressed through the very similar idea of behavioural "needs" (Bessei, 1980; Folsch, 1980; Wegner, 1980; van Putten, 1981), with the implication that animals suffer if they are unable to fulfill these needs, but the terms "needs" is so ill-defined (Dawkins, 1983b; Ewbank, 1985) that it does not clarify the issue at all. It still leaves the question of how strong a need has to be before the animal is said to be suffering (does a need to scratch a small itch constitute suffering?). We are back with the problem of measuring the strength of an animal's motivation to do something, whether we describe it as "deprivation" or "unmet need", and only when we can do that will we be able to relate either concept to that of "suffering".

\section{WHEN DOES DEPRIVATION BECOME SUFFERING?}

Deprivation becomes suffering when an animal is prevented (either through physical restraint or lack of suitable stimuli) from performing behaviour that it "wants" to do to such an extent that it experiences intense or prolonged unpleasant subjective feelings. In some cases, as with prevention of feeding behaviour, the deprivation eventually results in loss of physical condition and 
even death. Animals experience the unpleasant state of hunger when their food reserves become low enough to be life-threatening. Subjective feelings, including the unpleasant ones of "suffering", have a biological function (Baerends, 1973; Griffin, 1976; Dawkins, 1980; but see van Rooijen, 1981), in this case as part of a mechanism for restoring diminishing food reserves.

In other cases, as with the deprivation of dust-bathing in battery-caged hens, death may not result, but we still have to consider the possibility that intensely unpleasant subjective feelings result from the prevention of dust-bathing for exactly the same reason that they do in the case of hunger. This is that in nature deprivation of dust-bathing could be life-threatening (e.g. through lack of feather care leading to increased risk of predation from ineffective escape flight). Despite the possible genetic differences that may exist between our domestic animals and their wild ancestors (Beilharz and Zeeb, 1981), domestic animals are not man-made for confinement. They bring with them an evolutionary legacy from the past, and a large part of that evolutionary legacy is a mechanism for becoming most highly motivated to perform that behaviour which, at any one time, is most important to their survival and reproduction or, more precisely, where a failure to do the behaviour will result in the greatest cost (McFarland and Houston, 1981). We can easily see that deprivation of the opportunity to feed will lead to a state in which the animal's chances of survival are threatened; it will become highly motivated to feed and will suffer (both physically and mentally) if unable to do so. It is less easy for us decide whether deprivation of other behaviour, such as dust-bathing or fighting a rival, results in similar high motivation and suffering. Several different indicators have been used to establish whether or not deprivation does lead to high motivation to do prevented behaviour.

\section{a. Vacuum activities}

It has been argued (e.g. Black and Hughes, 1974; van Putten and Dammers, 1976; Vestergaard, 1980) that if animals perform behaviour in the absence of suitable stimuli (in a "vacuum"), ihey must be very highly motivated indeed. This view owes much to the models of Lorenz $(1950,1978)$, which have been extensively criticised (Hinde, 1970). One problem with using the observation that animals will perform behaviour with low levels or none of the normal stimuli is that the performance of the "vacuum" activity may itself reduce the motivation to perform the behaviour (cf. Heiligenberg, 1965).

\section{b. Accumulation or rebound effects}

Animals deprived of the opportunity to perform certain kinds of behaviour may sometimes show a greatly increased tendency to perform that behaviour when eventually given the opportunity (Wennrich and Strauss, 1977; Vester- 
gaard, 1980; Sambraus, 1982; Nicol, 1987). While this could sometimes be explained by the animals responding to the novelty of the opportunity given to them, the high levels of responding do, in at least some cases, seem to be due to the fact that motivation to do the prevented behaviour was indeed rising during the period of deprivation (Vestergaard, 1980; Metz, 1985; Nicol, 1987).

\section{c. Conflict, frustration and stereotypies}

With "vacuum activities", natural behaviour is performed in situations with inadequate stimuli. With "rebound" effects, it is performed at increased frequencies when the chance presents itself. However, there is another category where the animal may perform quite novel behaviour, or at least novel in its context.

For example, if an animal is physically prevented from reaching its food or does not find water where it has learnt to expect it, it may show a range of behaviour apparently unrelated to feeding or drinking such as pacing, aggression or grooming (e.g. Duncan, 1970; Roper, 1984).

If confined over a period of time, animals may develop "stereotypies" - fixed sequences performed repetitively with no obvious function such as bar-biting in tethered sows (Wiepkema et al., 1984). The causal basis of stereotypies is still unclear (Broom, 1983; Rushen, 1985; Appleby and Lawrence, 1987), and performing them may even form part of an animal's means of coping with a restricted environment through the release of endorphins (Dantzer et al., 1983; Weipkema et al., 1984). Nevertheless, when animals perform stereotypies for long periods of time (Broom, 1983, suggests $10 \%$ of the animal's waking life as a criterion), it is widely accepted that they are highly motivated to do behaviour that they cannot do, and that therefore their welfare must be impaired (Broom, 1983; McBride and Craig, 1985).

There are, then, a number of indicators that have been used for establishing high motivation in animals deprived of the opportunity for performing certain kinds of behaviour. All of them, however, have the same drawback; they still leave open the question of how high the prevented motivation has to be before we conclude that suffering is taking place. How much vacuum activity, how much of a rebound, how much stereotypy indicates suffering?

We may have evidence that depriving an animal of the opportunity to behave in certain ways may lead to high motivation to do that behaviour, but we still do not know how much that deprivation matters to the animal itself. To do that, we have to find ways of asking the animal how much it is prepared to pay to satisfy its deprivation. Deprivation becomes suffering when animals are kept without environments or opportunities to behave in certain ways which they will pay a high "cost" to obtain. 


\section{WHAT IS "COST"?}

For a biologist, "cost" means a decrease in inclusive fitness (Hamilton, 1964) which, more practically, can be reduced to meaning a drop in the offspring raised (Grafen, 1982). Thus the cost of being injured in a fight is the decrease in number of offspring that will be produced by an individual over its lifetime as a result of its injury (Maynard Smith, 1982); the cost of not eating an item of food is the effect on chances of survival and reproduction that not eating it will have (for a general discussion, see McNamara and Houston, 1986).

However this is "cost" measured by biologists who can, with skill, work out how many offspring are lost as a result of certain courses of action and how many are gained by others (e.g. Austed and Rabenold, 1985). In this, the biologist has a great deal in common with those who advocate that productivity and reproductive success should be the main measure of welfare (Craig and Adams, 1984). However, this is not the same as "cost" as it might appear to the animal, where what is important is the animal's own subjective assessment of the results of not doing (or being deprived of) something. Sometimes "cost" as measured by the biologist and "cost" as measured by an animal will coincide, as in the cost of not eating for a starving animal, where there is both a decrease in life expectancy and an increase in motivation to feed that rises to "suffering" as food reserves fall. Here suffering as experienced by the animal reflects impending death as assessed by a biologist or veterinarian.

The biologist's assessment of "cost" and that of an animal may not always coincide, however, particularly if the animal is kept in an environment very different from that which has shaped its behaviour over evolutionary time (Houston, 1988). For example, if a bird of a species that normally migrates in winter is kept in a cage, it may be well cared for and its chances of surviving the winter may be considerably greater than that of its wild counterpart that is free to fly south, but the caged bird does not know this. It may be highly motivated to fly (as judged by its repeated attempts to escape); so much so that it could be said to suffer from its confinement. Wild birds of this species may have little chance of survival if they do not migrate, so the caged one is behaving "as if" death were imminent. There is still a link between "likelihood of death" and "suffering", but it is not actual death but likelihood of death as assessed by the animal (Dawkins, 1983b). Similarly, the animal in a cage that is stared at by a well-meaning human may suffer just as much as the wild one being stared at by a hungry predator, even though the real chances of death in the two cases are vastly different.

So it is not just costs (fitness costs) as measured in actual chances of death and reproductive failure that matter, important though these are to the health of the animal, but "costs" as perceived by the animal (perceived costs). If the animal thinks it is in great danger as a result of not performing certain kinds of behaviour, then it may suffer, even though it may not be in actual danger. 
Having safeguarded the physical health of the animal, it is the costs as perceived by the animal that have now to concern us, even though the relationship between the two is far from simple (Dawkins, 1983b; A.I. Houston and J.M. McNamara, unpublished results).

\section{HOW CAN COST (AS PERCEIVED BY THE ANIMAL) BE MEASURED?}

\section{a. Preference tests and operant conditioning}

Animals can be offered choices between alternatives to see which one they prefer (preference tests), or trained to make some response such as pecking a key or pressing a lever to gain access to or avoid certain consequences (operant conditioning). Then, when the preferences have been established, the animals can be made to pay a "cost" (perceived cost), for example, having to peck a key or press a lever many times for the same reward to see whether it is still worth it for them.

Such methods have been used to study farm animal responses to different sorts of flooring (Hughes and Black, 1973; Hughes, 1976; Ponteaux et al., 1983; Irps, 1983; van Rooijen, 1985), different sized cages (Dawkins, 1981; Nicol, 1986; Faure, 1986), to the vibration and noise of a transport vehicle (Bailey et al., 1983), different temperatures and light levels (Richards, 1976; Curtis, 1983; Baldwin and Start, 1985; Morrison and McMillan, 1985) and many other factors (Kilgour, 1976; Beelharz and Zeeb, 1981).

If the animal's preference is still apparent when it has to work harder to gain access to its most preferred environment (e.g. by changing the number of bar presses for the same amount of reward), the animal is said to show "compensation" (Hogan and Roper, 1978), "resilience" (McFarland and Houston, 1981) or, to use the terminology that psychologists have borrowed from economics "inelastic demand" (Lea, 1978, 1980; Staddon, 1980; Hursh, 1984). This is a key concept for animal welfare (Dawkins, 1983b), since it provides a method of getting animals to show, through their behaviour, how important different environments or commodities are to them.

Not surprisingly, when food is the reward, animals usually appear to be prepared to work harder for the same amount of reward (Hogan et al., 1970; Collier et al., 1972; Marwine and Collier, 1979; Hursh, 1984), in other words, to show inelastic demand (Fig. 1). Other activities, such as responding to gain access to a rival (Thompson, 1964; Hogan et al., 1970) or gaining light (Findley, 1959), show elastic demand, that is, the animal's preference is apparent when the cost is low, but not when the animal has to work hard. The demand for water is inelastic in most animals (Hogan and Roper, 1978), but, interestingly, not in a species of packrat adapted to a very dry environment (Boice, 1984).

In general, it is to be expected that inelastic demand will be shown by animals for commodities (e.g. food) that are crucial to their survival and repro- 


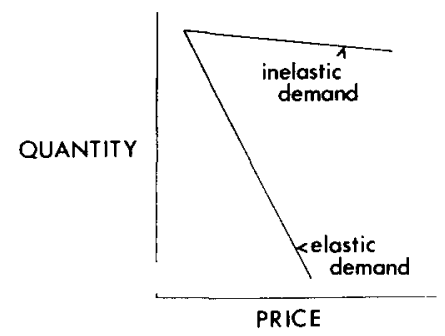

Fig. 1. Diagrammatic representation of elastic and inelastic demand. In economic terminology, inelastic demand is shown for commodities that are bought in much the same quantities whatever the price; elastic demand is shown for commodities that are bought in large quantities when the price is low, but decreasingly when the price rises. In biology, "price" can be altered by such means as requiring the animal to make a larger number of operant responses for the same amount of reward, increasing handling time, increasing the effort the animal must make, etc.

duction, i.e. where deprivation results in severe fitness costs and also in high costs as perceived by the animal. In wild animals in natural environments, this inelastic demand will have evolved precisely to ensure that the animal gives top priority to behaviour that will have the greatest fitness costs if not done.

Hursh (1984) argues that the analysis of behaviour in terms of demand curves (both the slope of the curve for different behaviours and the height of the curve above baseline) provides a unique and objective way of studying the strength of motivation. It is therefore potentially a unique and objective way of assessing welfare, since elasticity of demand may enable us to rank different behaviours in terms of their importance to the animal.

There are two methods of approach. The examples given so far have involved altering the price of individual commodities (such as the number of bar-presses needed to get a given amount of food), but it is also possible to alter the equivalent of "income" and therefore the price of all commodities together (Lea, 1978; Hursh, 1984). For example, Hill et al. (1988) increased or decreased the length of the light period given to growing chicks and therefore the time available for doing any behaviour normally done in the light. With short light periods, a given amount of time spent feeding would be costlier in terms of the time left over for other activities than when the light period was longer, since the total amount of time available (income) would be cut. These two methods of measuring elasticity of demand - manipulation of price and manipulation of total income - should give similar results (McFarland and Houston, 1981).

There are, however, certain problems with the interpretation of demand curves obtained by either method. Some of these problems arise from the fact that it may be more difficult to train animals to make operant response for some kinds of rewards than for others (Sevenster, 1973; Hogan and Roper, 1978; Roper, 1983; Dawkins and Beardsley, 1986). This may seriously confound the comparison between demand curves obtained for different reinfor- 
cers. A steeply sloping demand curve, suggesting elasticity of demand, may in fact reflect incompatibility of response and reinforcer, and not necessarily low motivation.

Other problems arise from the fact that short-term choices made in response to an immediate need may not reflect the animal's long-term preference. For example, hens about to lay have such a strong motivation to seek out nests that they will enter trap-nests even when the consequence is that they will have no food or water for the next $24 \mathrm{~h}$ (Duncan, 1978). If tested just before laying, they choose the nest; tested after laying, they choose food and water. Animals generally have a preference for immediate rather than long-term rewards (Timberlake, 1984).

These problems can be partially overcome (a) by measuring demand curves in ways other than bar-pressing and key-pecking, and where the response required of the animal is more closely related to the response it would make in the wild, and (b) by measuring demand curves over long periods of time, giving animals the opportunity to adjust and change their behaviour continuously (Collier et al., 1972).

This involves looking at the time-budgets of animals.

\section{b. Time-budget manipulations}

The way a freely moving wild animal behaves throughout the course of a day can be seen as the result of a series of choices or preferences between different behavioural options. The daily routines of wild animals and the amount of time they devote to different activities (their time-budgets) can be seen as strategies for coping with changes in the environment such as variations in temperature, activities of predators and abundance of food (Daan, 1981). Even in the absence of such changes in the environment, variability in energy expenditure may give rise to daily variations in behaviour (McNamara et al., 1988). Survival and reproduction will depend upon an animal allocating the right amount of time to different behaviour (Caraco et al., 1980a) and doing the behaviour at appropriate times of day, depending on such factors as food reserves (Metcalfe and Furness, 1984), risk of predation (Caraco et al., 1980a; Barnard, 1980 ), time available for doing the behaviour, results of behaviour earlier in the day, etc. (Katz, 1974; Houston and McNamara, 1982, 1985; McNamara and Houston, 1986; Mangel and Clark, 1986). Even the fact that many wild animals spend a high proportion of the "active" part of their days resting and apparently doing nothing (Herbers, 1981; Sutherland and Moss, 1985) can be regarded as an adaptive strategy, since periods of inactivity may be essential for digestion (Belovsky, 1981; Diamond et al., 1986), energy conservation (e.g. Anderson and Harwood, 1985) or avoiding predators.

Usually an animal can go through its daily routine and change from one behaviour to another only by making a specific response, such as flying from a 
food source to a waterhole or hunting and catching prey, and the cost of these transitions may alter at different times (Larkin and McFarland, 1978). Water and food may be different distances apart from one day to the next, or prey may run harder to get away depending on the season. So it is possible to ask animals how important their different activities are to them by seeing what happens when the costs are changed. This is thus analogous to altering schedules of reinforcement in an operant conditioning experiment, but using ways of altering cost that are closer to the natural environment in which the animal's behaviour (including the elasticity of its demands) evolved.

For example, Müller-Schwarze et al. (1982) experimentally reduced the milk supply of white-tailed deer fawns and found that they increased their grazing by $62 \%$ and achieved a virtually complete energy compensation, even though they had to reduce their other activities to achieve this. Gordon (1986) showed that this was even true in harvester ants, where experimental interference with foraging and nest maintenance resulted in the colony spending more time on collecting food at the expense of other activities. Domesticated animals, too, show major changes in their time-budgets in response to more or less concentrated food (Willard et al., 1977), more or less restricted environments (Houpt et al., 1986), and time of day for feeding (Albright and Pennington, 1984).

\section{DEMAND CURVES AND SUFFERING}

By experimentally manipulating time-budgets, we have a technique for asking animals which activities are most important to them through finding out the cost they are prepared to pay to do them. The measurement of demand curves for different activities and commodities enables us to gain an objective measure of motivational strength (Hursh, 1984) and to compare an animal's motivation for different activities.

Comparison of the slopes of demand curves for different activities would enable us to give a rank order of the importance of these to an animal. Suffering is most likely to occur if animals are deprived of activities/commodities with the shallowest demand curves (inelastic demand). Manipulations could include changing the time available for performing activities (Dawkins, 1983b) or placing obstacles in the animal's way (Nicol, 1986). Since food is generally acknowledged to be essential to good welfare and prolonged lack of food leads to clinical symptoms, a comparison between the demand curves for feeding and other activities may be used as a welfare yardstick. Commodities with similar demand curves to that shown for food can be regarded as essential to good welfare on the grounds that high motivation results from deprivation. Commodities with very elastic demand curves may be regarded as less essential to welfare. Where the line is drawn for intermediate slopes will be a matter of economics and judgement, but at least we can be reasonably sure that the most severe deprivations will be recognized and dealt with first. 


\section{CONCLUSIONS}

Since what we are seeking is a working definition of suffering, we can now use demand curves for several purposes.

(i) Suffering (in otherwise healthy animals) occurs when animals are kept in situations they will pay a high cost to get away from (aversion (Rushen, $1986 \mathrm{a}, \mathrm{b})$ ) or without stimuli/opportunities they will pay a high cost to obtain (deprivation; Section 2).

(ii) "High cost" may be defined by a demand curve with a shallow slope (inelastic demand), since this indicates that the commodity in question is important to the animal (Section 3). If it is similar in slope to the animal's demand curve for food, it can be concluded that deprivation of the commodity matters to the animal as much as food deprivation (Section 5 ).

(iii) Demand curves may be measured in two ways (Section 4); by changes of "income" or total time available to the animal for performing its entire behavioural repertoire, and by changes of the cost of individual behaviours. This can most conveniently be done by altering schedules in an operant conditioning experiment, but there may be problems with this approach that mean that, at least for some behaviour, time-budget manipulations of the animal in more natural environments may give better results.

\section{PROBLEMS WITH THIS APPROACH}

Although the analysis of demand curves is promising, it is not without its problems, and these must be thought through if the results are to be valid.

(i) The nature of the cost paid may affect the results (Section 4). The solution to this is to measure demand curves and to increase cost in several different ways (e.g. operant conditioning, length of light period, etc.) to make sure the apparent elasticity of demand is not an artefact.

(ii) The cost an animal is prepared to pay may depend on the availability of substitutes. The price rats are prepared to pay for food depends on whether or not sucrose is present (Lea and Roper, 1977). This is a consideration, but not a particular problem in welfare work; if an animal is not prepared to work hard for something because there are acceptable substitutes available, it is not suffering under the definition given above. The animal itself demonstrates this.

(iii) Demand curves may depend on whether the experiment is set up as an open or a closed economy (Collier et al., 1972; Hursh, 1984; Houston and McNamara, 1988). If the animal is put into the experimental set-up for just a short period each day and gets of its food, exercise, etc., outside the experiment sessions, its motivation to do one behaviour rather than another may appear quite different from situations in which it lives in the experimental set-up and has complete control over what it does throughout the day. For various reasons 
(Houston and McNamara, 1988), long-term, closed-economy experiments are more likely to give valid results.

(iv) The animal may not be able to plan far enough ahead to be able to make the right decisions for the whole day (Duncan, 1978; Timberlake, 1984; Kagel et al., 1986). This may again be because of the unnaturalness of some experimental situations. As for (iii), long-term experiments in which the animal is observed for long periods at a time are most likely to give valid results.

(v) The cost an animal is prepared to pay for something may depend on the predictability of the environment. For example, if there is some risk that food may not be found in the future, this may alter the attractiveness of a present food source (Caraco et al., 1980b; Stephens, 1981). Again this is not really a problem. It simply means that, in practice, the effect of predictability or lack of it has to be investigated.

(vi) What the animal chooses to pay for may not be best for its physical health in the long run, as pointed out by Duncan (1978) and van Rooijen (1984). As emphasised previously, the solution is to take into account other measures of welfare, not just one (Duncan, 1974; Dawkins, 1980; Kilgour, 1985).

(vii) There may be some states of "suffering" where an animal cannot be said to be motivated to do anything at all. For example, an animal might have a tumour, but it would be difficult to devise a situation in which it could show that it was highly motivated to get away from the tumour. The physical health of animals must always be the first criterion of their welfare, and demand curve analysis must go hand in hand with this.

(viii) Demand curves may be non-linear. For example, an animal may show apparently elastic demand for some commodity when the cost is increased at first, or grossly reduce the time it allocates to a particular behaviour when total time available is reduced. However, it may still be the case that, as the cost is increased still further, the animal "insists" on paying the cost. The only solution here is to make quite sure that the range of price-changes examined is sufficient to determine the true shape of the demand curve.

None of these objections is insuperable. They should be carefully considered in the design of any experiment, but they do not detract from the usefulness of demand-curve analysis in the objective assessment of a key problem in animal welfare.

\section{ACKNOWLEDGEMENTS}

I would like to thank Norma Bubier and Alastair Houston for their comments on the manuscript.

\section{REFERENCES}

Albright, J.L. and Pennington, J.A., 1984. The influence of diet upon time of calving and behaviour in dairy cattle. In: J. Unselm, G. Van Putten and K. Zeeb (Editors), Proc. Int. Congr. Applied Ethology in Farm Animals. KTBL, Darmstadt, pp. 184-188. 
Anderson, S. and Harwood, J., 1985. Time budgets and topography: how energy reserves and terrain determine the breeding behaviour of grey seals. Anim. Behav., 33: 1343-1348.

Appleby, M.C. and Lawrence, A.B., 1987. Food restriction as a cause of stereotypic behaviour in tethered gilts. Anim. Prod., 145: 103-110.

Austed, S.N. and Rabenhold, K.N., 1985. Reproductive enhancement by helpers and an experimental enquiry into its mechanism in the bicolored wren. Behav. Ecol. Sociobiol., 17: 19-27.

Baerends, G.P., 1973. Inleidung in: Ethologie, de biologie van gedrag. Biologisch raad reeks 7-16. Pudoc, Wageningen.

Bailey, K.J., Stephens, D.B., Ingram, D.L. and Sharman, D.F., 1983. The use of a preference test in studies of behavioural responses of pigs to vibration and noise. Appl. Anim. Ethol., 11: 197 (abstract).

Baldwin, B.A. and Start, I.B., 1985. Illumination preferences of pigs. Appl. Anim. Behav. Sci., 14: 233-243.

Banks, E.M., 1982. Behavioral research to answer questions about animal welfare. J. Anim. Sci., 54: 434-446.

Barnard, C.J., 1980. Flock feeding and time budgets in the house sparrow (Passer domesticus L.). Anim. Behav., 28: 295-309.

Barnett, J.L., Winfield, C.G., Cronin, G.M., Hemsworth, P.H. and Dewar, A.M., 1985. The effect of individual and group housing on behavioural and physiological responses related to the welfare of pregnant pigs. Appl. Anim. Behav. Sci., 14: 149-161.

Baxter, M., 1983a. Housing and welfare from first principles. In: S.H. Baxter, M.R. Baxter and J.A.C. MacCormack (Editors), Farm Animal Welfare and Housing. Martinus Nijhoff, The Hague, pp. 3-7.

Baxter, M.R., 1983b. Ethology in environmental design for animal prodution. Appl. Anim. Ethol., 9: $207-220$

Beilharz, R.G. and Zeeb, K., 1981. Applied ethology and animal welfare. Appl. Anim. Ethol., 7: 310.

Belovsky, G.E., 1981. Optimal activity times and habitat choice of moose. Oecologia, 48: 22-30.

Bessei, W., 1980. Essential behavioural needs: the mixed motivation approach. In: R. Moss (Editor), The Laying Hen and its Environment. Martinus Nijhoff, The Hague, pp. 167-180.

Black, A.J. and Hughes, B.O., 1974. Patterns of comfort behaviour and activity in domestic fowls: a comparison between cages and pens. Br. Vet. J., 130: 23-33.

Boice, R., 1984. Packrats (Neotoma albigula and N. micropus) compared in an operant analogue of foraging behaviors. J. Comp. Physiol., 98: 115-118.

Broom, D.M., 1983. Stereotypies as animal welfare indicators. In: D. Schmidt (Editor), Indicators Relevant to Farm Animal Welfare. Martinus Nijhoff, The Hague, pp. 81-87.

Brown, K.I., 1981. Scientific basis for assessing the well-being of animals in modern production. Poult. Sci., 60: 1630.

Caraco, T., Martindale, S. and Pulliam, H.R., 1980a. Avian flocking in the presence of a predator. Nature (London), 285: 400-401.

Caraco, T., Martindale, S. and Whitman, T.S., 1980b. An empirical demonstration of risk-sensitive foraging. Anim. Behav., 28: 820-830.

Collier, G., Hirsch, E. and Hamlin, P., 1972. The ecological determinations of reinforcement in the rat. Physiol. Behav., 9: 705-716.

Craig, J.V. and Adams, A.W., 1984. Behavior and well-being of hens (Gallus domesticus) in alternative housing environments. World's Poult. Sci. J., 40: 221-240.

Curtis, S.E., 1983. Perception of thermal comfort by farm animals. In: S.H. Baxter, M.R. Baxter and J.A.C. MacCormack (Editors), Farm Animal Welfare and Housing. Martinus Nijhoff, The Hague, pp. 3-7.

Daan, S., 1981. Adaptive daily strategies in behavior. In: J. Aschoff (Editor), Handbook of Behavioral Neurobiology. Vol. 4. Rhythms. Plenum, New York, pp. 275-298.

Dantzer, R., Mormede, P. and Henry, J.P., 1983. Physiological assessment of adaptation in farm 
animals. In: S.H. Baxter, M.R. Baxter and J.A.C. McCormack (Editors), Farm Animal Housing and Welfare. Martinus Nijhoff, The Hague, pp. 8-19.

Dawkins, M.S., 1980. Animal Suffering: the Science of Animal Welfare. Chapman and Hall, London.

Dawkins, M.S., 1981. Priorities in the cage size and flooring preferences of domestic hens. Br. Poult. Sci., 22: 255-263.

Dawkins, M.S., 1983a. The current status of preference tests in the assessment of animal welfare. In: S.H. Baxter, M.R. Baxter and J.A.C. McCormack (Editors), Farm Animal Housing and Welfare. Martinus Nijhoff, The Hague, pp. 20-26.

Dawkins, M.S., 1983b. Battery hens name their price: consumer demand theory and the measurement of ethological "needs". Anim. Behav., 31: 1195-1205.

Dawkins, M.S. and, Beardsley, T., 1986. Reinforcing properties of access to litter in hens. Appl. Anim. Behav. Sci., 15: 351-364.

Diamond, J.M., Karasov, W.H., Phan, D. and Carpenter, F.L., 1986. Digestive physiology is a determinant of foraging bout frequency in hummingbirds. Nature (London), 320: 62-63.

Duncan, I.J.H., 1970. Frustration in the fowl. In: B.M. Freeman and R.F. Gordon (Editors), Aspect of Poultry Behaviour. British Poultry Science, Edinburgh.

Duncan, I.J.H., 1974. A scientific assessment of welfare. Proc. Br. Soc. Anim. Prod., 3: 9-19.

Duncan. I.J.H., 1978. The interpretation of preference test in animal behaviour. Appl. Anim. Ethol., 4: 197-200.

Ewbank, R., 1985. Behavioural responses to stress in farm animals. In: G.P. Moberg (Editor), Animal Stress. American Physiological Society, Bethesda, MD, pp. 71-79.

Farm Animal Welfare Council, 1986. Egg Production Systems - An Assessment. Farm Animal Welfare Council, Tolworth, U.K.

Faure, J.-M., 1986. Operant determination of the cage and feeder size preference of the laying hen. Appl. Anim. Behav. Sci., 15: 325-336.

Findley, J.D., 1959. Behaviour output under chained fixed-ratio requirements in a 24 -hr experimental space. J. Exp. Anal. Behav., 2: 258 (abstract).

Folsch, D.W., 1980. Essential behavioural needs. In: R. Moss (Editor), The Laying Hen and its Environment. Martinus Nijhoff, The Hague, pp. 121-147.

Gordon, D.M., 1986. The dynamics of the daily round of the harvester ant colony (Pogonomyrmex barbatus). Anim. Behav., 34: 1402-1409.

Grafen, A., 1982. How not to measure inclusive fitness. Nature (London), 298: 425-446.

Griffin, D.R., 1976. The Question of Animal Awareness. Rockefeller University Press. New York.

Halliday, T., 1983. Motivation. In: T.R. Halliday and P.J.B. Slater (Editors), Animal Behaviour. Vol. 3. Causes and Effects. Blackwells Scientific, Oxford, pp. 100-133.

Hamilton, W.D., 1964. The genetical evolution of social behaviour. J. Theor. Biol., 7: 1-52.

Heiligenberg, W., 1965. A quantitative analysis of digging movements and their relationship to aggressive behaviour in cichlids. Anim. Behav., 13: 163-170.

Heiligenberg, W. and Kramer, U., 1972. Aggressiveness as a function of external stimulation. J. Comp. Physiol., 77: 332-340.

Herbers, J.M., 1981. Time resources and laziness in animals. Oecologia, 49: 252-262.

Hill, J.A., 1983. Indicators of stress in poultry. World's Poult. Sci. J., 39: 24-32.

Hill, W.L., Rovee-Collier, C., Collier, G. and Wasserloos, L., 1986. Time budgets in growing chicks. Physiol. Behav., 37: 353-360.

Hinde, R.A., 1970. Animal Behaviour. McGraw Hill, New York.

Hogan, J.A. and Roper, T.J., 1978. A comparison of the properties of different reinforcers. Adv. Study Behav., 8: 156-255.

Hogan, J.A., Kleist, S. and Hutchings, C.S.L., 1970. Display and food as reinforcers in the Siamese fighting fish (Betta splendens). J. Comp. Physiol. Psychol., 70: 351-357.

Houpt, K.A., O'Connell, M.F., Houpt, T.A. and Carbonaro, D.A., 1986. Night-time behavior of stabled and pastured peri-parturient ponies. Appl. Anim. Behav. Sci., 15: 103-111. 
Houston, A.I., 1987. The control of foraging decisions. In: M.L. Commons, A. Kacelnik and S.J. Shettleworth (Editors), Quantitative Analyses of Behavior. Vol. 6. Foraging. Lawrence Erlbaum, New York, pp. 41-61.

Houston, A.I. and McNamara, J., 1982. A sequential approach to risk taking. Anim. Behav., 30: 1260-1261.

Houston, A.I. and McNamara, J., 1985. The choice of prey types that minimizes the probability of starvation. Behav. Ecol. Sociobiol., 17: 135-141.

Houston, A.I. and McNamara, J.M., 1988. The value of food: effects of open and closed economies. Anim. Behav., in press.

Hughes, B.O., 1976. Preference decisions of domestic hens for wire or litter floors. Appl. Anim. Ethol., 2: 155-165.

Hughes, B.O., 1980. The assessment of behavioural needs. In: R. Moss (Editor), The Laying Hen and its Environment. Martinus Nijhoff, The Hague, pp. 149-166.

Hughes, B.O. and Black, A.J., 1973. The preference of domestic hens for different types of battery cage floor. Br. Poult. Sci., 14: 615-619.

Hursh, S.R., 1984. Behavioral economics. J. Exp. Anal. Behav., 42: 435-452.

Irps, H., 1983. Results of a research project into flooring preferences of cattle. In: S.H. Baxter, M.R. Baxter and J.A.C. MacCormack (Editors), Farm Animal Housing and Welfare. Martinus Nijhoff, The Hague, pp. 200-215.

Kagel, J.H., Green, L. and Caraco, T., 1986. When foragers discount the future: constraints or adaptation? Anim. Behav., 34: 271-283.

Katz, P.L., 1974. A long-term approach to foraging optimization. Am. Nat., 108: 758-782.

Kilgour, R., 1976. The contributions of psychology to a knowledge of farm animal behaviour. Appl. Anim. Ethol., 2: 197-205.

Kilgour, R., 1985. The definition, current knowledge implementation of welfare for farm animals - a personal view. Advances in Anim Welfare Science, 1985/86, The Humane Society of the United States.

Larkin, S. and McFarland, D.J., 1978. The cost of changing from one activity to another. Anim. Behav., 26: 1237-1246.

Lea, S.E.G., 1978. The psychology and economics of demand. Psychol. Bull., 85: 441-466.

Lea, S.E.G., 1980. Supply as as factor in motivation. In: F.M. Toates and T.R. Halliday (Editors), Analysis of Motivational Processes. Academic Press, New York, pp. 153-177.

Lea, S.E.G. and Roper, T.J., 1977. Demand for food on fixed-ratio schedules as a function of concurrently available reinforcement. J. Exp. Anal. Behav., 27: 371-380.

Loliger, H.C., 1985. Poultry health as a criterion of welfare. In: R.M. Wegner (Editor), 2nd Eur. Symp. Poultry Welfare. German Branch of the W.P.S.A., Celle, F.D.R., pp. 56-62.

Lorenz, K., 1950. The comparative method in studying innate behaviour patterns. Symp. Soc. Exp. Biol., 4: 221-268.

Lorenz, K., 1978. Vergleichende Verhaltensforschung. Springer, Vienna.

Mangel, M. and Clark, C.W., 1986. Towards a unified foraging theory. Ecology, 67: 1127-1138.

Martin, G., 1975. Uber Verhaltensstorungen von Legehennen im Kafig. Ein Beitrag zur Klarung des Problmes tierschutzgerechter Huhnerhaltung. Angew. Ornothol., 4: 145-176.

Marwine, A. and Collier, G., 1979. The rat at the waterhole. J. Comp. Physiol. Psychol., 93: 391402.

Maynard Smith, J., 1982. Evolution and the Theory of Games. Cambridge University Press, Cambridge.

McBride, G. and Craig, J.V., 1985. Environmental design and its evaluation for intensively housed animals. Appl. Anim. Behav. Sci., 14: 211-224.

McFarland, D.J. and Houston, A.I., 1981. Quantitative Ethology. Pitman, London.

McNamara, J.M. and Houston, A.I., 1986. The common currency for behavioral decisions. Am. Nat., 127: 358-378. 
McNamara, J.M., Mace, R.H. and Houston, A.I., 1987. Optimal daily routines of singing and foraging in a bird singing to attract a mate. Behav. Ecol. Sociobiol., 20: 399-405.

Metcalfe, C.A., Johnson, D.F. and Collier, G., 1984. Allocation of time as a function of cost of activities in rats. Paper presented at the meeting of the Eastern Psychological Association, Baltimore.

Metcalfe, N.B. and Furness, R.W., 1984. Changing priorities: the effects of pre-migratory fattening on the trade-off between foraging and vigilance. Behav. Ecol. Sociobiol., 15: 203-206.

Metz, J.H.M., 1985. The reaction of cows to a short-term deprivation of lying. Appl. Anim. Behav. Sci., 13: 301-307.

Morrison, W.D. and McMillan, I., 1985. Operant control of the thermal environment by chicks. Poult. Sci., 64: 91-94.

Müller-Schwarze, D., Stagge, D.B. and Müller-Schwarze, C., 1982. Play behavior: persistence, decrease and energetic compensation during food shortage in deer fawns. Science, 25: 85-87.

Nicol, C.J., 1986. Non-exclusive spatial preference in the laying hen. Appl. Anim. Behav. Sci., 15: $337-350$.

Nicol, C.J., 1986. A study of the behavioural needs of battery-housed hens. D. Phil. Thesis, University of Oxford.

Nicol, C.J., 1987. Behavioural responses of laying hens following a period of spatial restriction. Anim. Behav., 35: 1709-1719.

Ponteaux, V.A., Christison, G.I. and Stricklin, W.R., 1983. Perforated-floor preference of weanling pigs. Appl. Anim. Ethol., 11: 19-23.

Rawlins, J.N.P., Feldon, J., Salmon, P., Gray, J.A. and Garrud, P., 1980. The effects of chlodiazepoxide $\mathrm{HCl}$ administration upon punishment and conditioned suppression in the rat. Psychopharmacology, 70: 317-322.

Richards, S.A., 1976. Behavioural temperature regulation in the fowl. J. Physiol., 258: 122P-123P.

Roper, T.J., 1983. Learning as a biological phenomenon. In: T.R. Halliday and P.J.B. Slater, (Editors), Animal Behaviour. Vol. 3. Genes, Development and Learning. Blackwell Scientific, Oxford, pp. 178-212.

Roper, T.J., 1984. Response of thirsty rats to absence of water: frustration, disinhibition or compensation? Anim. Behav., 32: 1225-1235.

Rushen, J.P., 1985. Stereotypies, aggression and the feeding schedules of tethered sows. Appl. Anim. Behav. Sci., 14: 137-147.

Rushen, J., 1986a. The validity of behavioural measures of aversion: a review. Appl. Anim. Behav. Sci., 16: 309-323.

Rushen, 1986b. Aversion of sheep for handling treatments: paired-choice studies. Appl. Anim. Behav. Sci., 16: 363-370.

Russell, W.M.S. and Burch, R.L., 1959. The Principles of Humane Experimental Technique. Methuen, London.

Sambraus, H.H., 1982. Ethologische Grundlagen einer tiergerechten Nutztierhaltung. Tierhaltung, 13: 23-41.

Sevenster, P., 1973. Incompatibility of response and reward. In: R.A. Hinde and J. StevensonHinde (Editors), Constraints on Learning: Limitations and Predispositions. Academic Press, London, pp. 265-283.

Smidt, D. (Editor), 1983. Indicators Relevant to Farm Animal Welfare. Martinus Nijhoff, The Hague.

Staddon, J.E.R., 1980. Optimality analysis of operant behaviours and their relation to optimal foraging. In: J.E.R. Staddon (Editor), Limits to Action: The Allocation of Individual Behavior. Academic Press, New York, pp. 101-141.

Stephens, D.W., 1981. The logic of risk-sensitive foraging. Anim. Behav., 29: 628-629.

Sutherland, W. and Moss, D., 1985. The inactivity of animals: the influence of stochasticity and prey size. Behaviour, 92: 1-8. 
Thompson, T.I., 1964. Visual reinforcement in fighting cocks. J. Exp. Anal. Behav., 7: 45-49.

Thorpe, W.H., 1965. The assessment of pain and distress in animals. In: F.W.R. Brambell (Chairman), Report of the Technical Committee to Enquire into the Welfare of Animals kept under Intensive Livestock Systems. H.M.S.O., London, pp. 71-79.

Thorpe, W.H., 1967. Discussion to Part II. In: T.C. Carter (Editor), Environmental Control in Poultry Production. Oliver and Boyd, Edinburgh, pp. 125-134.

Timberlake, W., 1984. A temporal limit on the effect of future food on current performance in an analogue of foraging and welfare. J. Exp. Anal. Behav., 41: 117-124.

Tschantz, B., 1978. Reaktionsnormen und Adaptation. In: W.H. Wicke, (Editor), Das Tier im Experiment. Hans Huber, Bern, pp. 33-49.

Tschantz, B., 1982. Verhalten, Bedarf und Bedarfsdeckung bi Ntztieren. In: Aktuelle Arbeiten zur artgemasses Tierhaltung, 281, 1981, KTBL, Darstadt, pp. 114-128.

Van Putten, G., 1981. Restriction of induced behaviour Appl. Anim. Ethol., 7: 387-388 (abstract).

Van Putten, G. and Dammers, J., 1976. A comparative study of the well-being of piglets reared conventionally and in cages. Appl. Anim. Ethol., 2: 339-356.

Van Rooijen, J., 1981. Are feelings adaptations? The basis of modern applied animal ethology. Appl. Anim. Ethol., 7: 187-198.

Van Rooijen, J., 1984. Impoverished environments and welfare. Appl. Anim. Behav. Sci., 12: 313.

Van Rooijen, J., 1985. Ontogeny and preference tests with pigs. Appl. Anim. Behav. Sci., 14: 388389.

Vestergaard, K., 1980. The regulation of dustbathing and other behaviour patterns in the laying hen: a Lorenzian approach. In: R. Moss (Editor), The Laying Hen and its Environment. Martinus Nijhoff, The Hague, pp. 101-113.

Wegner, R.-M., 1980. Measurement of essential and behavioural needs as provided by present husbandry systems: battery, "get-away", aviary. In: R. Moss (Editor), The Laying Hen and its Environment. Martinus Nijhoff, The Hague, pp. 195-205.

Wennrich, G. and Strauss, D.D., 1977. A contribution to the evidence of motivational accumulation in domestic hens (Gallus gallus domesticus). Dtsch. Tieraerztl. Wochenschr., 84: 293332.

Wiepkema, P.R., Cronin, G.M. and van Ree, J.M., 1984. Stereotypies and endorphins: functional significance of developing stereotypies in tethered sows. In: J. Unshelm, G. van Putten and K. Zeeb (Editors), Proc. Int Congr Applied Ethology in Farm Animals, Kiel. KTBL, Darmstadt, pp. 93-96.

Willard, J.G., Willard, J.C., Wolfram, S.A. and Baker, J.P., 1977. Effect of diet on cecal pH and feeding behaviour of horses. J. Anim. Sci., 45: 87-93.

Wood-Gush, D.G.M., 1973. Animal welfare in modern agriculture. Br. Vet. J., 129: 167-173.

Zayan, R. and Duncan, I.J.H., 1987. Cognitive Aspects of Social Behaviour in the Domestic Fowl. Elsevier, Amsterdam. 